\title{
DESAFIOS E POTENCIALIDADES EM INTERVENÇÕES CURRICULARES NA PERSPECTIVA DA ABORDAGEM TEMÁTICA
}

\author{
MARINÊS VERÔNICA FERREIRA ${ }^{*}$ \\ https://orcid.org/0000-0002-2097-8415 \\ CRISTIANE MUENCHEN ${ }^{1 * *}$ \\ https://orcid.org/0000-0003-3144-0933 \\ DÉCIO AULER ${ }^{\text {II *** }}$ \\ https://orcid.org/0000-0001-8802-1428
}

RESUMO: O presente trabalho tem por objetivo identificar, analisar e socializar configurações curriculares, na área de Ciências da Natureza, estruturadas mediante a abordagem temática e, com isso, sinalizar possíveis encaminhamentos para constituição de currículos estruturados nesta perspectiva. Participaram da pesquisa treze professores do Ensino Médio de Escolas Estaduais de Santa Maria/ RS. Da análise emergiram as categorias: Formação inicial de professores: dificuldades no desenvolvimento de intervenções curriculares na perspectiva de temas; Investigação Temática: limites apontados na definição do tema; Intervenções curriculares: dificuldades quanto à organização do tempo para planejamento na escola; Interdisciplinaridade: desafios a serem enfrentados; Engajamento:potencialidadedestacada nodesenvolvimento dos trabalhos e intervenções curriculares a partir da abordagem temática: aprendizagem como potencialidade destacada. Espera-se que este trabalho contribua na visibilidade às práticas de reorientação curricular que estão sendo desenvolvidas em ambientes escolares, favorecendo a reflexão docente com relação tanto às potencialidades como às alternativas de minimização das dificuldades vivenciadas pelas intervenções curriculares realizadas.

Palavras-chave: Abordagem temática; Currículo; Ensino Médio.

\section{DESAFÍOS Y POTENCIALIDADES EN INTERVENCIONES CURRI- CULARES EN LA PERSPECTIVA DEL ENFOQUE TEMÁTICO}

RESUMEN: El objetivo de este trabajo es identificar, analizar y socializar configuraciones curriculares, en el área de Ciencias de la Naturaleza, estructuradas mediante el planteamiento

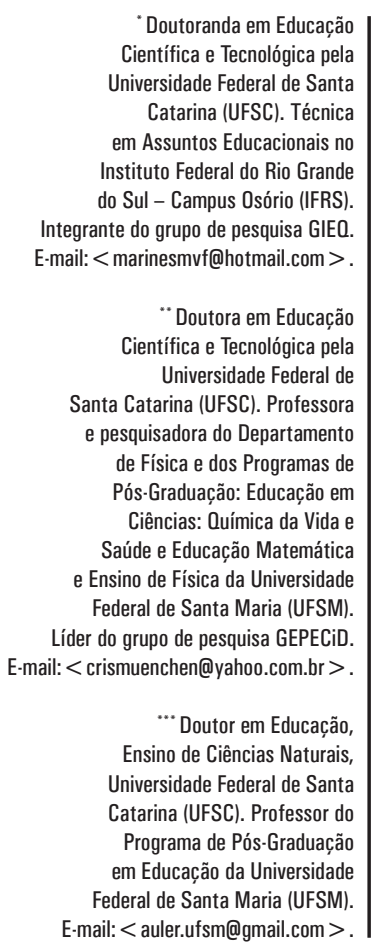

“Doutoranda em Educação Científica e Tecnológica pela Carsidade Federal de Santa Catarina (UFSC). Técnica em Assuntos Educacionais no Instituto Federal do Rio Grande Integrante do grupo de pesquisa GIEO. E-mail:<marinesmvf@hotmail.com>.

“* Doutora em Educação entífica e Tecnológica pela Universidade Federal de Santa Catarina (UFSC). Professora pesquisadora do Departamento Pós-Graduação: Educação em Ciências: Química da Vida e Saúde e Educaça Matemática Federal de Santa Maria (UFSM). Líder do grupo de pesquisa GEPECiD. E-mail: < crismuenchen@yahoo.com.br > .

*** Doutor em Educação Ensino de Ciências Naturais, Universidade Federal de Santa Catarina (UFSC). Professor do Programa de Pós-Graduação em Educação da Universidade E-mail:< auler.ufsm@gmail.com>. de Física e dos Programas de

\footnotetext{
' Instituto Federal do Rio Grande do Sul, Osório, RS - Brasil.

" Universidade Federal de Santa Maria, Departamento de Física, Santa Maria, RS - Brasil.

I' Universidade Federal de Santa Maria, Programa de Pós-Graduação em Educação, Santa Maria, RS - Brasil.
} 
temático y, con ello, señalar posibles encaminamientos para la constitución de currículos estructurados en esta perspectiva. Participaron de la investigación trece profesores de la Enseñanza Media de Escuelas del estado de Santa Maria / RS. Del análisis surgieron las categorías: Formación inicial de profesores: dificultades en el desarrollo de intervenciones curriculares en la perspectiva de temas; Investigación Temática: límites señalados en la definición del tema; Intervenciones curriculares: dificultades en cuanto a la organización del tiempo para la planificación en la escuela; Interdisciplinariedad: desafíos a afrontar; Compromiso: potencialidad destacada en el desarrollo de los trabajos e intervenciones curriculares a partir del planteamiento temático: aprendizaje como potencialidad destacada. Se espera que este trabajo contribuya a la visibilidad de las prácticas de reorientación curricular que se están desarrollando en ambientes en los entornos escolares, favoreciendo la reflexión docente con relación tanto a las potencialidades como a las alternativas de minimización de las dificultades que experimentan las intervenciones curriculares realizadas.

Palabras clave: Enfoque temático; Plan de estudios; Enseñanza Media.

\section{CHALLENGES AND POTENTIALITIES IN CURRICULAR INTERVENTIONS IN THE PERSPECTIVE OF THE THEMATIC APPROACH}

ABSTRACT: The objective of this work is to identify, analyze and socialize curricular configurations, in the area of Natural Sciences, structured through the thematic approach with this to indicate possible referrals for the constitution of curricula structured in this perspective. Thirteen teachers from the State High School of Santa Maria / RS participated in the research. From the analysis emerged the categories: Initial teacher training: difficulties in the development of curricular interventions in the perspective of themes; Thematic Research: limits indicated in the definition of the theme; Curricular interventions: difficulties in organizing time for school planning; Interdisciplinarity: challenges to be faced; Engagement: outstanding potential in the development of the works and Curricular interventions from the thematic approach: learning as outstanding potential. It is hoped that this work will contribute to the visibility of the curricular reorientation practices being developed in school environments, favoring teacher reflection regarding both the potentialities and the alternatives to minimize the difficulties experienced by the curricular interventions carried out.

Keywords: Thematic approach; Curriculum; High school. 


\section{INTRODUÇÃO}

O Ensino Médio é reconhecido como etapa da educação geral, na qual o indivíduo deverá ser preparado para o trabalho e para sua inserção social cidadã. Assim, pode perceber-se sujeito de intervenção no seu próprio processo histórico, atento às transformações da sociedade, de forma a compreender os fenômenos sociais e científicos que permeiam o seu cotidiano e, ainda, possibilitar a continuação de seus estudos (BRASIL, 1996).

Nesse sentido, Meszáros (2005, p. 12) corrobora ao demarcar que "a educação teria como função transformar o trabalhador num agente político, que pensa, que age, e que usa a palavra como arma para transformar o mundo", aproximando-se de Freire (2001a) e dos aportes teóricos que reforçam a importância e o papel da educação na construção da consciência crítica, sendo essa uma maneira de educar que contribui para as pessoas analisarem a realidade vivida, de forma a torná-las capazes de agir sobre essa realidade, transformando-a.

Como proposta de superação da educação propedêutica e fragmentada que ainda vigora nos espaços escolares, trazendo consequências como, por exemplo, a falta de interesse e motivação do estudante em relação ao ensino desenvolvido pela escola, defende-se, por exemplo, que o professor supere o papel de repetidor de currículos, enfrentando o desafio de concebê-los (AULER, N e AULER, 2015). A perspectiva da Abordagem Temática, que de acordo com Delizoicov, Angotti e Pernambuco (2011, p. 189) pode ser entendida como: “[...] uma perspectiva curricular cuja lógica de organização é estruturada com base em temas, com os quais são selecionados os conteúdos de ensino das disciplinas. Nesta abordagem a conceituação científica da programação é subordinada ao tema" buscando superar um ensino fortemente ligado a um currículo pautado na compartimentalização/disciplinarização do saber.

Como possibilidade de estruturação de currículos que tenham maior significado para os educandos e como forma também de contribuir para construção de uma compreensão de mundo alinhada à busca de uma sociedade mais justa e democrática, defende-se uma estruturação curricular crítica, destacando-se a Abordagem Temática Freireana (ATF) ${ }^{1}$ constituída

[...] a partir da situação presente, existencial, concreta, refletindo o conjunto de aspirações do povo, que poderemos organizar o conteúdo programático da educação ou da ação política. O que temos de fazer, na verdade, é propor ao povo, através de certas contradições básicas, sua situação existencial, concreta presente, como problema que, por sua vez, o desafia e, assim, lhes exige resposta, não só no nível intelectual, mas no nível da ação. (FREIRE, 1987, p. 100).

Nessa perspectiva, a organização curricular está atrelada à seleção de temas que emergem da investigação na comunidade escolar. ${ }^{2}$ Dessa forma, tanto a organização quanto a seleção dos conteúdos, a serem trabalhados com os estudantes, são selecionadas intencionalmente para a compreensão do tema, denominado de Tema Gerador, constituído contradições sociopolíticas relevantes e presentes naquela comunidade (AULER, DALMOLIN e FENALTI, 2009). 
Ressalta-se que, na ATF, trabalha-se com questões que emergem de situações que fazem parte da vida do educando, sobre as quais, de algum modo, terá algo a falar, já que possui conhecimentos de mundo (FREIRE 1997) sobre os temas a serem abordados. Parte-se do saber de experiência feito para a construção de novos conhecimentos. Nesse contexto, a construção do conhecimento não acontece no vazio, buscando-se transformar a aprendizagem como algo instigante para o educando. Conforme Delizoicov, Angotti e Pernambuco (2011), os temas geradores

[...] foram idealizados como um objeto de estudo que compreende o fazer e o pensar, o agir e o refletir, a teoria e a prática, pressupondo um estudo da realidade em que emerge uma rede de relações entre situações significativas individual, social e histórica, assim como uma rede de relações que orienta a discussão, interpretação e representação dessa realidade. (2011, p. 165). que favoreça

Mediante essa abordagem temática, propõe-se uma estruturação curricular

[...] uma visão de totalidade e abrangência da realidade, a ruptura com o conhecimento no nível do senso comum, adotar o diálogo como sua essência, exigir do educador uma postura de crítica, de problematização constante, de distanciamento, de estar na ação e de se observar e se criticar nessa ação, apontar para a participação, discutindo no coletivo e exigindo disponibilidade dos educadores (DELIZOICOV, ANGOTTI, PERNAMBUCO, 2011, p. 166).

A ATF, proposta por Delizoicov, Angotti e Pernambuco (2011), é inspirada em Paulo Freire, principalmente na obra Pedagogia do Oprimido (FREIRE, 1987). A transposição da concepção freireana, para a educação formal, realizada por esses autores, foi tomando forma a partir dos projetos realizados na Guiné Bissau (DELIZOICOV, 1980, 1982, 1983, 1994), no Rio Grande do Norte (PERNAMBUCO, 1988, 1993, 1994) e no município de São Paulo (SÃO PAULO, 1990, 1992). Com esta transposição, busca-se romper com o currículo tradicional reduzido a abordagem de conceitos. Conforme Delizoicov, Angotti e Pernambuco (2011), o aspecto mais importante, nessa abordagem, consiste numa nova relação entre o currículo e a comunidade escolar, uma vez que o currículo passa a ser estruturado a partir de temas, bem como o planejamento didáticopedagógico dos educadores.

Nessa concepção curricular, o coletivo de educadores tem a possibilidade de planejar/organizar o conteúdo programático gerado pelas situações vivenciadas pelo educando, de forma a ser debatido, estudado e compreendido por este, possibilitando a transformação da sua realidade. Sampaio, Quadrado e Pimentel (1994, p. 59) enfatizam que o "tema gerador se coloca com um referencial para permitir a leitura crítica da sociedade e significa o ponto de partida de uma intervenção na direção de rumos da sociedade".

Nesse sentido, estudos mais recentes (TORRES, 2010; WATANABECARAMELLO e KAWAMURA, 2006; STRIEDER et al., $2011 \mathrm{e}$ HALMENSCHLAGER, 2014) têm aprofundado a pertinência de currículos 
temáticos, apontando desafios, potencialidades e, acima de tudo, caminhos a serem explorados mediante o uso da abordagem temática.

Com esses pressupostos, buscou-se, nessa pesquisa, identificar desafios ${ }^{3}$ e potencialidades ${ }^{4}$ encontradas mediante o uso da abordagem temática, na Educação em Ciências Naturais, a partir de intervenções curriculares realizadas em Escolas Estaduais de Ensino Médio de Santa Maria/RS.

\section{PROCEDIMENTOS METODOLÓGICOS}

Decorrente do objetivo, identificar potencialidades e desafios a partir de professores de Ciências da Natureza que vivenciaram intervenções curriculares na perspectiva da abordagem temática, estruturou-se o procedimento de investigação. Primeiramente foi necessário delimitar a amostra a ser investigada, optou-se então pelas Escolas Estaduais de Ensino Médio de Santa Maria/RS. Precisava-se, assim, identificar a presença da abordagem de temas nas práticas pedagógicas das escolas públicas estaduais de Ensino Médio de Santa Maria/RS. O processo de identificação das escolas ocorreu pela análise dos Projetos Pedagógicos (PP) das vinte (20) escolas estaduais do município e pela investigação de pesquisas na perspectiva da abordagem temática que ocorreram nestas escolas na área de Ciências da Natureza.

Dessa etapa investigativa, foi possível identificar quatro (4) escolas, duas (2) através dos PP e duas (2) pelos trabalhos de pesquisas desenvolvidos a partir da intervenção curricular na perspectiva da Abordagem Temática. Assim, seis (6) intervenções foram objeto de análise, das quais treze (13) professores ${ }^{5}$ aceitaram fazer parte da pesquisa. Na figura 1, sintetiza-se essa amostra.

Figura 1. Representação sintetizada da amostra da pesquisa

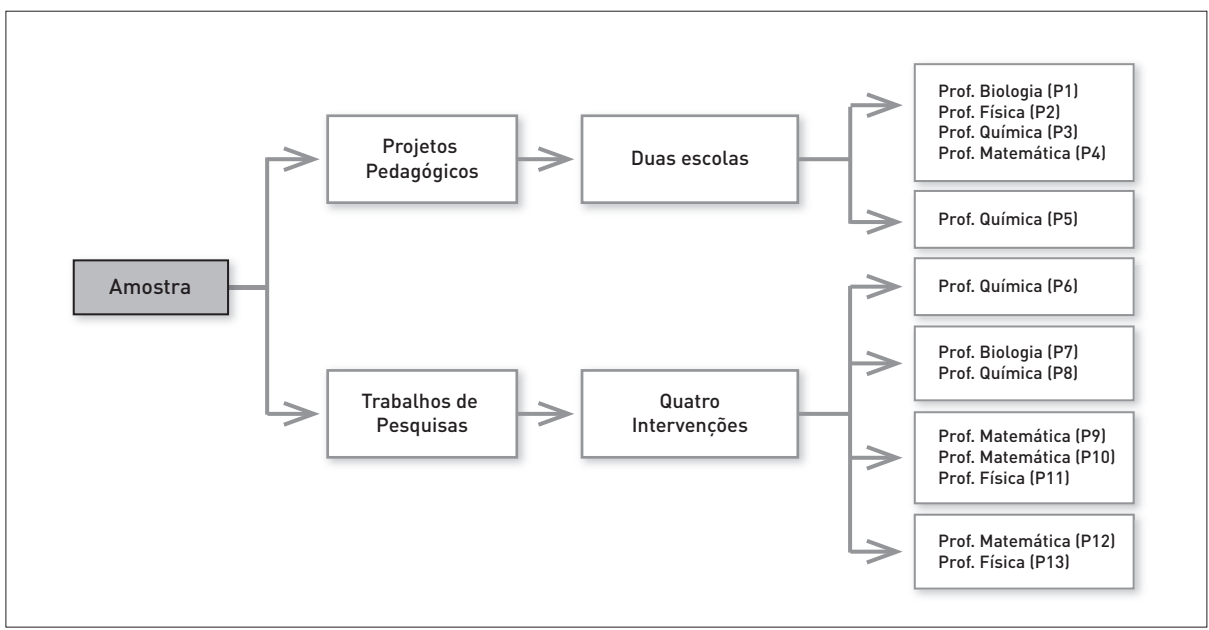

Como técnica de produção de dados, realizaram-se entrevistas de caráter semiestruturado. Inicialmente, planejaram-se questões para a realização de uma entrevista piloto de maneira a analisar a capacidade das questões atenderem ao objetivo do trabalho. A entrevista piloto foi realizada com um pesquisador que havia 
proposto uma das intervenções curriculares, de maneira a validar o instrumento. Posteriormente realizaram-se as entrevistas com professores das áreas das Ciências da Natureza que tinham participado de experiências com a abordagem temática.

Para a análise dos materiais coletados, utilizou-se a Análise Textual Discursiva (ATD), caracterizada por Moraes (2003) e Moraes e Galiazzi (2006; 2011). Segundo Moraes e Galiazzi (2006), a ATD é descrita como:

[...] um processo que se inicia com uma unitarização em que os textos são separados em unidades de significado. Estas unidades por si mesmas podem gerar outros conjuntos de unidades oriundas da interlocução empírica, da interlocução teórica e das interpretações feitas pelo pesquisador. Depois da realização desta unitarização, que precisa ser feita com intensidade e profundidade, passa-se a fazer a articulação de significados semelhantes em um processo denominado de categorização. Neste processo reúnem-se as unidades de significado semelhantes, podendo gerar vários níveis de categorias de análise. A análise textual discursiva tem no exercício da escrita seu fundamento enquanto ferramenta mediadora na produção de significados e por isso, em processos recursivos, a análise se desloca do empírico para a abstração teórica, que só pode ser alcançada se o pesquisador fizer um movimento intenso de interpretação e produção de argumentos. Este processo todo gera metatextos analíticos que irão compor os textos interpretativos. (2006, p. 118).

Na Análise Textual Discursiva, a unitarização e a categorização constituemse como etapas em que novas compreensões são produzidas. Como característica da ATD, Moraes e Galiazzi (2011, p. 132) apontam para etapas como: “[...] recortados pulverizados, desconstruídos, sempre a partir das capacidades interpretativas do pesquisador". Esta fase é compreendida como momento em que o pesquisador estabelece uma relação íntima, profunda com os materiais coletados na pesquisa. Nessa etapa, são construídas várias interpretações para um mesmo registro que, ao final, resulta nas unidades de significados.

Na segunda etapa, conforme Moraes (2003, 197), tem-se a categorização, que se caracteriza por um "processo de comparação constante entre as unidades definidas no processo inicial de análise, levando ao agrupamento de elementos semelhantes". Entretanto, alguns critérios precisam ser seguidos, pois constroemse as categorias por meio dos elementos semelhantes, sendo que a todo o momento elas podem ser modificadas e reorganizadas num processo em espiral. Como afirmam Moraes e Galiazzi (2011, p. 125), “[...] as categorias não saem prontas, e exigem um retorno cíclico aos mesmos elementos para sua gradativa qualificação". Com as categorias "extraídas", possibilita-se a emergência de uma nova compreensão do todo, que é comunicado e validado, resultando o metatexto.

Desse processo de diálogo entre unidades de significado, referenciais teóricos e objetivos da pesquisa, resultaram as categorias que serão discutidas a seguir.

\section{RESULTADOS E DISCUSSÕES}

Conforme já referido, os elementos obtidos na entrevista semiestruturada foram analisados fazendo-se uso da Análise Textual Discursiva (ATD) (MORAES, 2003; MORAES, GALLIAZZI, 2013). Também já destacado, o processo de 
análise foi guiado por dois olhares, um buscando identificar os desafios e outro as potencialidades do trabalho na perspectiva temática, os quais estão contemplados na discussão das seis categorias que seguem.

\section{FORMAC̣̃̃O INICIAL DE PROFESSORES: DIFICULDADES NO DESENVOLVIMENTO DE INTERVENÇ̃̃ES CURRICULARES NA PERSPECTIVA DE TEMAS}

Diante dos resultados, foi possível perceber lacunas no processo de formação inicial que, por vezes, é apontado como o limitador ao professor para articular e desenvolver trabalhos por temas. Falas de professores entrevistados trazem essas sinalizações:

No meu curso foi só disciplina, né, o que não propicia essa ideia, algumas alternativas que aconteceram foi por que eu busquei [...] (P2)

A minha formação deixou muito a desejar, tanto que eu só consegui trabalhar quando eu fui buscar por mim. Eu não aprendi a trabalhar na sala de aula durante minha formação [...]. Na universidade, não tem isso [...] (P5)

[...] a universidade não me preparou para trabalhar assim, eu tive muitas disciplinas, mas nenhuma fez algum tipo de discussão desse tipo. [...] (P12)

Essas falas aproximam-se das discussões trazidas por Delizoicov, Angotti e Pernambuco (2011, p. 34) quando se referem à necessidade de uma reformulação na atuação e formação dos professores na área de Ciências da Natureza, as quais apresentam lacunas e fragilidades decorrentes do ensino estar baseado em um currículo fragmentado, conteudista e voltado à "formação de cientistas", o que dificulta o desenvolvimento de um currículo estruturado na abordagem de temas. Tais fragilidades, na formação docente, também foram sinalizadas por Araújo (2015) que constata a necessidade de uma formação que possibilite ao docente sair do estado de transmissor de conceitos científicos, o qual tem como objetivo atender tão somente aos processos de avaliação, ou seja, buscam que os " [...] educandos processem as informações lançadas em aulas e apresentem bons resultados em posteriores avaliações" (2015, p. 80).

Para Freire (2001b, p. 72), um dos problemas decorrente dos processos pautados nas avaliações é que "em lugar de apostar na formação dos educadores, esse sistema, baseado no autoritarismo, aposta nas suas 'propostas' e na avaliação posterior para ver se o 'pacote' foi realmente assumido e seguido". A essas discussões Freire defende que "[...] formar é muito mais do que puramente treinar o educando no desempenho de destrezas". (FREIRE, 1997, p. 15). Fragilidades formativas, para a atuação na perspectiva da abordagem temática, estão evidenciadas nas manifestações de professores anteriormente citadas.

É possível constatar que os professores se sentem despreparados e inseguros: "Eu não me sinto em condições com esse modelo por temas, eu não me sinto preparada, não tive essa formação [...]” (P1). Com relação ao despreparo, Militão (2012, p. 747) aponta para o problema da "formação docente 
nos cursos superiores" que está formando professores desqualificados devido ao processo acelerado no qual o objetivo é a certificação em massa e não a formação propriamente dita. Decorrente deste tipo de formação, o professor acaba por apresentar dificuldades com relação à transformação dos seus saberes e saberes-fazeres, e com relação à aproximação desses conhecimentos a formas que propiciem a construção do conhecimento pelo estudante.

Professores também apontam limites, em seu processo formativo, que dificultam a saída do estado de executores de currículo para a ação de concebê-los, ou seja, "Isso é um abismo entre tudo né, minha formação é conteudista, é aquilo ali, tem que dar no primeiro ano, isso no segundo, aquilo ali e, assim por diante" (P4). Em contrapartida, Hunsche e AULER (2012) e Moraes (2008) sinalizam para a necessidade de avanços em que o ponto de partida seja o contexto do estudante, havendo dessa forma, outra lógica na concepção de currículos, sendo a realidade e o contexto dos estudantes sinalizadores de conhecimentos disciplinares necessários.

Contudo, mesmo que a formação tenha sido totalmente conteudista, há formas que auxiliam o professor a suprir deficiências deixadas por esse tipo de formação. Uma delas, segundo Freire (1997), consiste em entender que enquanto se ensina também se aprende.

Ainda em relação a fragilidades formativas, para o professor P7, “[...] a universidade tem que participar mais das escolas [...] as disciplinas da licenciatura têm que serem revistas, eu acho que está muito fora da realidade”. O professor P8 sinaliza que "a nossa formação pedagógica ela tinha que ser repensada dentro da universidade para que os alunos consigam sair daqui, com pelo menos o mínimo necessário [...]”. As falas de ambos os professores parecem evidenciar uma formação de natureza técnico-instrumental, desenvolvendo uma concepção fragmentada da docência.

Referindo-se à formação inicial, Freire sugere uma "educação em favor da emancipação permanente dos seres humanos” (FREIRE, 2006a, p. 72). Dessa forma, a perspectiva da formação dos professores se ancora em uma proposição que requer a criação e a organização de situações problematizadoras da realidade, considerando o educando e o educador. Assim, a aprendizagem não estará limitada aos conteúdos disciplinares, embora não sejam excluídos e não se restringirá a aquisição de metodologias do ensinar e do aprender, as quais também não são desconsideradas. Ainda, não se limitará ao saber fazer pedagógico, embora também esse não seja descartado. Nesta perspectiva, o educador é tido não como uma realidade pronta e acabada, mas como um construtor de conhecimentos que requer a aprendizagem do pensar, do refletir rigoroso, crítico e problematizador.

\section{INVESTIGAC̣ÃO TEMÁTICA: LIMITES APONTADOS NA DEFINIC̣ÃO DO TEMA}

Dentre os objetivos propostos para realização da presente pesquisa, buscou-se conhecer quais as concepções dos professores frente ao trabalho por temas, ou seja, como ocorre a definição do tema e qual o papel que esse assume frente ao currículo adotado pela escola. Quando questionados sobre a definição do tema, professores responderam que 
O tema é definido pelos professores, inclusive o último a gente definiu em reunião na biblioteca, é uma reunião fechada, tem uns minutos para conversa com a supervisora, isso foi feito dentro do semestre, aí a supervisora faz o questionamento para os professores sobre qual o tema que eles gostariam de trabalhar, aí surge algumas ideias, e dentro delas a gente escolhe aquela que acha melhor. (P1)

Os professores escolhem o tema relacionado com a atualidade, alguma coisa assim, que tá na mídia, então a gente procura relatar com alguma coisa que tem a ver com a atualidade com o dia a dia deles, mas o tema é escolhido pelos professores. (P2)

O caminho seguido, na definição do tema, por algumas escolas, demonstra que consideraram apenas o contexto do professor. Essa forma de seleção acaba por priorizar a dimensão do conteúdo em detrimento do sujeito da aprendizagem, o estudante. Segundo Delizoicov, Angotti e Pernambuco (2011), isso é decorrente de preocupações que estão voltadas muito mais para o desempenho da ação docente e pouco se tem pensado sobre o efeito dessa sobre o estudante. Talvez alguns questionamentos precisassem ser levantados, como: Que tipo de aprendizagem está sendo propiciada? O currículo está adequado ao meio do estudante? Quais as justificativas para a sequência de conteúdos em livros didáticos e guias curriculares? Será que o estudante é o foco da aprendizagem?

Considerando os referenciais assumidos, na ATF, existe a necessidade de conhecer o estudante que está constituindo as salas de aula. Ou seja, "quem é esse estudante? como ele aprende?” (DELIZOICOV, ANGOTTI e PERNAMBUCO, 2011, p. 122). Mas, como responder tais questões, sem antes conhecer esse sujeito, que, muitas vezes, é considerado muito mais como categoria do que sujeito concreto. Entende-se, assim, que pouco se sabe sobre os estudantes: quem são, o que esperam da escola, o que os preocupa, como aprendem. É fundamental a reflexão da escola sobre esses itens, pois essas dimensões são deixadas de lado ou são pouco consideradas quando o estudante não participa, não tem voz, não é ouvido.

Houve professores que, ao serem questionados sobre a forma de definição do tema, colocaram que esse foi levado pelo pesquisador ${ }^{6}$ que estava desenvolvendo trabalho na escola. Apontam, ainda, para a existência de interação da escola com a pesquisa, a partir do momento em que a definição do tema aconteceu pela investigação da realidade:

[...] investigar um tema que fosse de acordo com aquela realidade. (P8)

Foram pesquisas na comunidade que levaram ao tema infraestrutura. (P10)

Nesse tema houve uma entrevista, entrevista não, foi um questionário com os alunos né, que a mestranda desenvolveu com os alunos, com os professores, com a equipe diretiva e com a comunidade. (P11)

Eu lembro que houve várias saídas no bairro para investigar os problemas e, como o Arroio Cadena faz parte desta comunidade e representa um problema para todos nós, isso acabou, foi por isso que foi escolhido o tema Arroio Cadena. (P12) 
Cabe destacar que o processo de investigação temática também foi relatado por outros professores. O professor P6, mesmo tendo optado por um tema transversal, entende que "na verdade o tema surge na escola [...]" (P6). Assim, compreende-se que o tema surge da realidade da escola e do estudante que constitui a escola. Com isso, o trabalho, na área de Ciências da Natureza, aproxima-se do que defendem Delizoicov, Angotti e Pernambuco (2011), ao postularem que os conhecimentos científicos estejam relacionados com a vida das pessoas, abarcando questionamentos com relação a decisões políticas e econômicas.

Houve, também, processo de investigação temática que se aproximou bastante das etapas propostas por Freire (1987),

Daí então, desenvolvi as cinco etapas, a primeira a investigação preliminar da realidade onde, eu, fiz o questionário. Eu fiz entrevista com cerca de cento e cinquenta pessoas, da comunidade e do entorno, entre professores, pais, funcionários de prefeituras, postos policiais. Então eu fiz todo um levantamento dessa realidade, da realidade da comunidade escolar. Certo, daí depois que eu fiz essa etapa, fiz essa etapa, os professores não me ajudaram. Eu fiz sozinha essas entrevistas. Aí eu achei, eu acho, eu tinha que envolver mais eu acho que preciso de mais apoio, é um trabalho muito complexo. Então na segunda etapa, eu, falei vou fazer com os professores, então, nós sentamos, mostrei os dados que a gente tinha e a gente construiu umas redes temáticas, pora sistematizar essa ideia. $\mathrm{Na}$ verdade para sistematizar quais eram aqueles temas que pertenciam aquela comunidade. Se os temas eram significativos para aquela comunidade. Então, construímos essas redes. (P8)

Conforme Alves, Carvalho e Mion (2009) “a partir da investigação temática se permite conhecer o que os alunos pensam, como pensam e porque é desse ou daquele modo que pensam [...]". Por esse motivo, a investigação temática é considerada o "germe da reconstrução curricular" (2009, p. 12). Inicia-se a busca pela identidade profissional e ética do professor, já que o processo de investigação e reflexão sobre a ação possibilita ao educador assumir-se à medida que constrói a sua prática.

Para Freire, o trabalho com temas favorece o desenvolvimento de um olhar crítico do estudante sobre sua realidade, possibilitando, através da incorporação de conhecimentos científicos, analisar rigorosamente e entender situações problemas que fazem parte do mundo vivido por ele. Desse modo, propiciando ao estudante, a partir de problemas sociais, construir uma visão de mundo mais significativa, potencializando para a realização de análises mais críticas sobre fatos e problemas, posicionando-se.

\section{INTERVENÇ̃̃ES CURRICULARES: DIFICULDADES QUANTO À ORGANIZAÇÃO DO TEMPO PARA PLANEJAMENTO NA ESCOLA}

A discussão sobre reestruturação curricular, particularmente aquela concebida segundo a abordagem temática, requer tempo. Tempo de planejamento, tempo de estudo, de pesquisa, tempo de execução, tempo de avaliação. Tempos que se entrecruzam. Contudo, na fala de professores,

[...] a maioria dos professores tem uma carga horária em sala de aula que não permite isso[...] (P2) 
Pelo fato dos professores trabalharem em mais de uma escola, os professores trabalham em duas, três até quatro escolas diferentes. (P5)

Para Santiago e Batista Neto (2011, p. 13), “[...] é no tempo/espaço e com eles que o processo de formação ocorre, na dimensão inicial e continuada, assim como na diversidade e nas possibilidades de espaços de aprendizagens e formação”. No momento em que o professor não dispõe desse tempo/espaço, na escola, tais dimensões como: troca de experiências, reflexões, socializações, organização do funcionamento escolar, interações sociais e as relações inter-extra escolares são comprometidas. Acima de tudo, fica limitado o trabalho coletivo, fundamental em ações com currículos temáticos, os quais requerem equipes multidisciplinares.

Além das anteriores, outras manifestações foram tecidas quanto a insuficiência de tempo para o planejamento,

$[\ldots]$ o planejamento precisa de tempo e quando temos tempo? [...] (P2)

[...] não existe um planejamento. (P4)

O professor não tem tempo para planejar [...] (P8)

Essas falas remetem a outras questões. Por exemplo, se o professor não tem tempo para planejar, terá tempo para refletir sobre a ação que realizou, sobre o seu fazer pedagógico? Quais eram os objetivos que permearam a ação pedagógica realizada? Tais objetivos, foram alcançados? Qual a relação do fazer pedagógico com o sujeito da aprendizagem? Ainda, nesse caso, quem é o sujeito da aprendizagem?

Limitações à reconfiguração curricular, mediante a abordagem temática, considerando o fator tempo, também foram apontadas pelo professor P2, dizendo que, “[...] não tem como sentar e planejar". A partir de Freire entende-se que o planejamento educacional deve dialogar com a sociedade,

[...] tem que responder às marcas e aos valores dessas sociedades. Só assim é que pode funcionar o processo educativo, ora como força estabilizadora, ora como fator de mudança. [...] para ser autêntico, é necessário ao processo educativo que se ponha em relação de organicidade com a contextura da sociedade a que se aplica. (FREIRE, 2001a, pg. 10)

A ausência de um efetivo planejamento compromete o processo educacional, reduzindo-o a um fazer pedagógico pouco significativo. Para Vasconcelos (1995, p. 43), o planejamento é processo de reflexão, tomada de decisão “[...] enquanto processo, ele é permanente". No entanto, o planejamento, por ser uma ação humana, assume uma dimensão política. Assim, mesmo que esse não ocorra, sua ausência estará traduzindo determinada opção política, muitas vezes, imposta aos professores.

Professores como, por exemplo, P3, salientam que "a gente não planeja de forma conjunta [...]". Segundo o professor P8, isto justifica-se "[...] primeiro por falta de tempo [...]" e o professor P2 acrescenta a essa discussão que "[...] 
tenho um cronograma para seguir [...]" e que a possibilidade de encontrar-se com os colegas professores cada vez está mais restrita, conforme a própria fala do professor, "a gente encontra um tempo para falar na hora do recreio [...]".

A desqualificação dos professores, para Arroyo (1985), vem sendo uma forma de mantê-los fracos e disponíveis às manobras e conchavos político-burocráticos. O autor propõe aprofundar a formação de profissionais críticos-reflexivos, que questionem a própria formação e combatam interesses elitistas e excludentes.

Desqualificação também é manisfestada quando a formação reduz-se a conceitos específicos. Para Freire,

[...] somente um ser que é capaz de sair de seu contexto de "distanciar-se" dele para ficar com ele capaz de admirá-lo para, objetivando-o, transformá-lo e, transformando-o, saberse transformado pela sua própria criação um ser que é e está sendo no tempo que é o seu, um ser histórico, somente este é capaz, por tudo isto, de comprometer-se.(1979, p. 8).

Transparece, nas falas desses professores, considerando as adversidades, principalmente a falta de tempo para planejamento, certo grau de conformismo e, inclusive, de resignação.

\section{INTERDISCIPLINARIDADE: DESAFIOS A SEREM ENFRENTADOS}

$\mathrm{Na}$ abordagem temática, a interdisciplinaridade é entendida como sendo um olhar coletivo de diversos campos de conhecimento para a compreensão de um tema ou fenômeno. Assim, “[...] pressupõe um procedimento que parte da ideia de que as várias ciências deveriam contribuir para o estudo de determinados temas que orientariam todo o trabalho escolar" (DELIZOICOV e ZANETIC, 1993, p. 13), contribuindo para a construção de compreensões cada vez mais complexas e mais amplas em torno das situações problemas. A interdisciplinaridade prioriza a organização do pensamento dos sujeitos como uma nova forma de interpretação da realidade, para poder atuar sobre ela. No entanto, ela está imbricada na ressignificação do aprender e do ensinar, conforme vem sendo discutido neste trabalho.

Para Delizoicov e Zanetic (1993), a interdisciplinaridade ocorre com respeito a especificidade de cada área do conhecimento. Assim, a fragmentação somente é necessária para um diálogo inteligente com o mundo, cuja gênese encontra-se na evolução histórica do desenvolvimento do conhecimento. Dessa forma, "[...] ao invés do professor polivalente, a interdisciplinaridade pressupõe a colaboração integrada de diferentes especialistas que trazem a sua contribuição para a análise de determinado tema" (idem, 1993, p. 13). A interdisciplinaridade pode ser um novo modo de reorganização das disciplinas científicas e uma maneira de reformulação das estruturas de ensino que, muitas vezes, podem provocar atitudes de insegurança e de recusa por se constituir num desafio. Conforme P13, essa, " [...] rompe como os paradigmas das disciplinas tradicionais, da disciplina engavetada".

Como possibilidade de desenvolver o conhecimento de forma mais ampla e concreta, defende-se a construção e compreensão dos temas a partir da contribuição das diferentes áreas do conhecimento, conforme o olhar do professor P12 “[...] a gente tentava ver o tema, mas cada um olha a partir de sua área”. Desta maneira, 
conforme Moraes (2008, p. 23) "trabalhar de forma interdisciplinar é superar a fragmentação dos conteúdos [...], ser interdisciplinar é contextualizar o ensino”.

Por outro lado, quando os professores são questionados sobre qual a relação entre o tema e o conteúdo científico, a professora $\mathrm{P} 4$ manifesta que "O mesmo acontece com a Física tem temas que não tem como a gente colocar". O professor refere-se a incompatibilidade entre determinados temas e os conhecimentos de seu campo de atuação. No entanto, essa falta de relação entre tema e conceitos científicos pode ser reflexo do isolamento disciplinar vivido pelos docentes. Também conforme Delizoicov e Zanetic (1993), qualquer transformação, no campo educacional, não é uma tarefa fácil, indo ao encontro da fala do professor P6, “[...] demora um pouquinho para isso".

O professor P6 destaca que as mudanças não acontecem na velocidade que, muitas vezes, se deseja, o processo é lento. Centa (2015, p. 68) confirma trazendo que "o trabalho coletivo e interdisciplinar é um processo". A velocidade do processo decorre de "problemas conceituais, operacionais e recursos humanos" (DELIZOICOV, ZANETIC, 1993 p. 9). Conforme os mesmos autores, a busca por soluções dos problemas vão surgindo no trabalho interdisciplinar, que constrói novos conhecimentos, uma vez que o enfrentamento de problemas é "característica essencial da produção de conhecimento".

A professora P3 discorre sobre a dificuldade em encontrar parceiros em outras disciplinas, "[...] A gente tenta, mas é difícil, ninguém quer participar, primeiro por falta de tempo, inexperiência mesmo, sinto falta de ter alguém, um orientador. Assim, acaba por não ter contribuição das outras disciplinas". Esse excerto aproximase de Araújo (2015) e Pernambuco (1994) que entendem que pode ser comprometido o conhecimento no trabalho por temas pela ausência de contribuições de outras áreas do conhecimento. Assim, a interdisciplinaridade considera a complexidade de um tema, exigindo a análise "sob vários olhares disciplinares articulados em torno de um tema constituído de um problema” (AULER, 2007, p.7).

Apesar das falas de professores denunciarem dificuldades a serem enfrentadas, percebem-se avanços quanto ao entendimento da necessidade do trabalho coletivo.

[...] as vezes tu te obriga a revisar algumas coisas né, o aluno tem dificuldades, no caso minha área é química e eu acabo tendo que ir um pouco para a matemática e para a física revisar algumas coisas que eles ainda têm dificuldades. Nada é isolado né, tudo é uma continuação. (P3)

Através da fala desse professor percebe-se que há um entendimento quanto à compreensão de algo mais amplo, sendo possibilitado através dos olhares das diferentes áreas de conhecimento. Conforme definem Delizoicov e Zanetic:

É como se um fenômeno ou situação fossem vistos através de uma lente que os decompõe segundo as diferentes luzes do conhecimento (física, química, biologia, história, geografia, artes, etc.), permitindo revelar aspectos fragmentados da realidade. Estes, integrados, permitem melhor compreensão daquele fenômeno ou situação. (1993, p.13). 
Dessa forma, possibilita-se uma compreensão mais crítica do contexto em que vive o estudante, havendo para tal, a necessidade da contribuição de diversas áreas do conhecimento, aspecto indicado por P6, ao assinalar que "[...] entender um fenômeno tem que ir para o aspecto histórico, geográfico, aí teria que integrar [...]", ou seja, aproximação de várias áreas contribuindo para a compreensão do fenômeno estudado, características que estão em sintonia com a perspectiva da ATF.

A interdisciplinaridade requer, acima de tudo, o encontro de pessoas, o que, na atual organização do espaço-tempo da escola, fica bastante comprometido. Isolamento também uma característica, cada vez mais marcante, do contexto social mais amplo. Em outros termos, a interdisciplinaridade, requerida pela abordagem temática, requer repensar o espaço-tempo de organização da escola, repensar condições de trabalho dos professores. Repensar em diálogo com a problematização da dinâmica social mais ampla, pautada pelo individualismo crescente.

A aprendizagem do educando está relacionada ao seu grau de motivação, ou seja, entende-se que a aprendizagem é intensificada quando há motivação com o que está sendo trabalhado. Para Freire e Shor (1986), a motivação está imbricada à prática docente "[...] a motivação faz parte da ação. É um momento da própria ação. Isto é, você se motiva à medida que está atuando, e não antes de atuar” (1986, p.15).

A partir da fala de professores, destaca-se a motivação decorrente das intervenções curriculares realizadas nas escolas. Os docentes destacam que se sentiram motivados, participaram com maior entusiasmo, "[...] eles participaram, assim, de uma maneira com uma metodologia, essa metodologia fez com que participassem bastante" (P7). Por outro lado, P11 sinaliza que, com o trabalho na perspectiva de temáticas, os estudantes "[...] se motivam a aprender cada vez mais e a gente se aproximou mais [...]". Isso está relacionado, conforme Ferrão e Auler (2012), ao fato das aulas ganharem sentido para os estudantes, visto que esses estão acostumados a trabalhar com "muitas fórmulas, cálculos, textos, muitos dos quais sem sentido" (p.162).

$\mathrm{Na}$ concepção curricular estruturada mediante a abordagem temática, Delizoicov e Angotti (1990, p. 29) sinalizam que o professor assume a postura de um problematizador. Segundo esses autores, o professor, ao problematizar o estudante, origina a dúvida com relação ao fenômeno discutido. Desse modo, acaba desafiando o estudante na busca de ampliar seus conhecimentos. Para o professor P5, “[...] trabalhar com temáticas, o trabalho é mais eficaz [...], há uma aproximação, eu percebo que o aluno quebra aquele gelo com o colega, com o professor e, com o conteúdo. Ele diz, ah, agora eu entendi prof.".

Com essa concepção de educação, o professor passa a desenvolver, junto aos estudantes, uma capacidade crítica e de curiosidade para perguntar, conhecer, reconhecer e atuar. Segundo P12, “[...] os alunos sempre foram muitos envolvidos, eu nunca vi eles tão envolvidos, como se envolveram com o projeto. Nas aulas participavam, perguntavam, eles abraçaram o projeto [...]". Ainda, "[...] é um trabalho que nos proporciona novos conhecimentos e experiências [...]". Essas experiências são problematizadoras do currículo tradicional que está, conforme apontado pelo mesmo professor, "dissociado da aprendizagem experiencial extraescolar dos estudantes".

Segundo P8, a reestruturação curricular mediante a abordagem temática " [...] é um trabalho que mexe com as concepções das pessoas, mexe com as ideias [...]". 
Para o professor P5, o trabalho por temas proporciona "[...] a proximidade entre a teoria e a vida do aluno, até a vida do professor”. Essa aproximação é propiciada pela contextualização do tema discutido, pois, dessa maneira, o conhecimento passa a fazer sentido por estar relacionado ao contexto no qual o estudante está inserido.

Na abordagem temática, para Delizoicov, Angotti e Pernambuco (2011), assume-se a sala de aula como

[...] espaço de trocas reais entre alunos e entre eles e o professor, diálogo que é construído entre conhecimentos sobre o mundo onde se vive e que, ao ser um projeto coletivo, estabelece a mediação entre as demandas afetivas e cognitivas de cada um dos participantes. (p. 153)

Nessa concepção de educação, o foco não está na preocupação com listas de conteúdos a serem depositadas nos estudantes, ou situação relatada pelo professor P4, na qual “[...] não conseguem colocar o conteúdo dentro do tema”[...]. Essa concepção tradicional, para Japiassu (1976), resulta num processo fragmentado, no qual a preocupação está vinculada em cumprir currículos previamente estipulados e pouco vinculados à realidade do aluno.

\section{INTERVENÇÕES CURRICULARES A PARTIR DA ABORDAGEM TEMÁTICA: APRENDIZAGEM COMO POTENCIALIDADE DESTACADA}

Segundo Freire (2003), aprendizagem é o resultado de uma curiosidade do sujeito, o que o torna construtor de novos conhecimentos. Entende-se que o aprender envolve os conhecimentos prévios (sua visão de mundo) dos educandos, assim como o despertar de sua curiosidade pela busca de novos conhecimentos. Nesse sentido, pode-se dizer que o processo de ensino-aprendizagem envolve pesquisa e a disposição em aprender e em ensinar, ou seja, depende tanto de quem ensina quanto de quem aprende, sendo entendido por Freire (1997) que, "ensino porque busco, porque indaguei, porque indago e me indago. Pesquiso para constatar, constatando, intervenho, intervindo, educo" (p. 32). Ou seja, a aprendizagem está entrelaçada à curiosidade e à forma com que é trabalhada com o educando.

A partir do processo de pesquisa, da interação de elementos teóricos e empíricos, obteve-se a aprendizagem dos estudantes como uma potencialidade na perspectiva do trabalho na Abordagem Temática. Nesse sentido, o professor P5 destaca que "[...] por tema a aprendizagem é melhor [...]". Também o professor P2 colabora trazendo que "[...] tu percebe uma melhor aprendizagem dos alunos". De alguma forma, essas falas remetem aos educadores Freire e Snyders, citados por Delizoicov, Angotti e Pernambuco (2011, p. 189) que "propõem um ensino baseado em temas", que possibilite ao estudante romper com fragmentação e disciplinarização do ensino.

Aspectos contextuais precisam ser ponto de partida e de chegada no processo de ensino e aprendizagem (HALMENSCHLAGER, 2014). Com isso, rompe-se o paradigma tradicional, da pura conceituação científica, buscando a abordagem de conteúdos relevantes e significativos, tornando a proposta mais dinâmica e participativa.

Aproximando-se dessa compreensão, comparece a fala de P13, "a gente trabalhou pra que eles pudessem entender o que acontece com o rio, por que ele está naquela situação". As palavras do professor relacionam-se com as observações de 
Halmenschlager (2014), quando se refere à perspectiva temática como situação em que,

[...] o aluno precisa participar ativamente do processo de ensino, não somente no sentido de realizar todas as tarefas que o professor propõe, mas de modo que suas visões de mundo sobre o conteúdo escolar em estudo sejam apreendidas e problematizadas. Conteúdo que pode ser tanto o dito científico quanto o contextual. (p. 109)

Compreende-se, portanto, a importância das situações problemas serem do contexto social do aluno, pois, assim, será potencializado a necessidade da aprendizagem dos conceitos científicos (HALMENSCHALAGER, 2014).

Segundo P8, “[...] se eles conseguem entender dentro de um contexto, eles, conseguem aplicar em todos os contextos que aparecem para eles". Isso se deve, conforme Halmenschlager (2014), ao trabalho por temas que,

[...] permite uma articulação entre temas e conceituação científica, cuja perspectiva não é simplesmente a de se abordar conceitos científicos, mas sim planejar sua abordagem com a finalidade de que eles, ao serem apropriados, possibilitem uma compreensão do tema diferenciada daquela que se tinha, antes desses conceitos terem sido apropriados pelos alunos (p.171).

Cabe a ressalva de que, na perspectiva temática, a aprendizagem não acontece só ao nível do estudante, já que o professor também aprende com o mesmo, com as dúvidas e colocações por ele apresentadas, bem como de elementos oriundos do contexto social mais amplo. Nesse sentido, a perspectiva da abordagem temática aproxima-se de Nóvoa (1995). Segundo esse autor, na aprendizagem sempre há troca de experiências e a partilha de saberes possibilita a formação mútua, pois cada professor exerce duas funções simultaneamente: o papel de formador e de formando.

\section{CONSIDERAC̣ÕES FINAIS}

Ao procurar investigar desafios e potencialidades no processo de abordagem temática, a partir das falas de professores que vivenciaram alguma intervenção nessa concepção curricular, foi possível identificar seis categorias, as quais sintetizam os resultados da pesquisa.

Com relação à formação inicial, os professores evidenciaram dificuldades / fragilidades quanto as suas formações nos cursos de graduação, as quais não contemplam a dimensão de desenvolver outras perspectivas curriculares. As colocações dos professores relacionaram-se diretamente ao currículo dos cursos e ao fazer didático-pedagógico desses profissionais. Nesse sentido, fazem reflexões no que tange à formação acadêmica dos futuros professores, sinalizando a necessidade de revisão dos currículos dos cursos de licenciatura na área das Ciências da Natureza. Como encaminhamento, aponta-se a necessidade da universidade considerar formas de aproximar os licenciados à realidade escolar em tempo superior ao período de realização dos estágios curriculares. Assim, considera-se que estaria sendo possibilitado, aos acadêmicos, maior convívio com a realidade das escolas de Ensino Básico, o que poderia contribuir tanto na formação docente 
quanto na própria docência segundo os entrevistados. Desta forma, pode-se questionar tanto as reformulações no ensino como o próprio "artigo 22" da LDB, que discorre sobre a finalidade da escolarização para o desenvolvimento do indivíduo de forma integral, pois os professores denunciam suas dificuldades.

Outro resultado da pesquisa refere-se à definição do tema. Alguns professores explicitaram não saber trabalhar por temas e desconhecer a perspectiva da abordagem temática. Sendo assim, professores tentam desenvolver o trabalho por temas, mas permanecem vinculados a listas de conteúdos e/ou não exploram as diferentes potencialidades e possibilidades presentes nessa concepção curricular. O tema é considerado, por alguns, como um conteúdo isolado dos conhecimentos científicos. Dessa forma, em algumas situações, define-se um tema para que os alunos 'pesquisem' em espaços virtuais. Além disso, os professores tiveram suas formações pautadas no "ensino bancário" (FREIRE, 1987), sendo esse o exemplo de trabalho didático-pedagógico que conhecem. Assim, pode-se entender as diferentes concepções e encaminhamentos dados às intervenções, algumas delas aproximando-se, particularmente na definição do tema, dos pressupostos da Investigação Temática Freireana.

Outro desafio relaciona-se à organização do tempo para planejamento. A abordagem temática requer uma organização espaço-temporal distinta da que, atualmente, predomina nas escolas. Mesmo assim, professores convictos do potencial de currículos pensados em torno de temas, planejavam nos finais de semana, após chegarem em casa das escolas. Aqui, o desafio vai muito além do estritamente pedagógico. Implica na luta política por políticas públicas para a educação.

Desafios que se colocam para o trabalho interdisciplinar, diretamente vinculados à abordagem temática, consistiram outra dimensão identificada na pesquisa. Desafio relacionado à discussão anterior, ou seja, a falta de tempo e de espaços nos quais pessoas possam se encontrar, requisito fundamental para um trabalho interdisciplinar. Desafio que também implica na problematização da formação inicial disciplinar e fragmentada desses professores. Além de desafios, comparecem, também, na pesquisa, indícios de potencialidades, de sinalizações promissoras quanto ao trabalho interdisciplinar.

Os desafios identificados, na pesquisa, apontam que o trabalho, na perspectiva temática, ainda demanda uma longa caminhada, exigindo, tanto ao nível docente, passando pelas licenciaturas, quanto da escola, um efetivo enfrentamento desses para possibilitar sua disseminação. Disseminação que tem ocorrido, possivelmente, também, pelos potenciais evidenciados por essa concepção de organização curricular. Também as dificuldades sinalizadas pelos professores reforçam a necessidade da educação ser repensada conforme Freire traz em suas obras. Além disso, esse cenário educacional trazido pelos professores confirma a predominância do ensino propedêutico e fragmentado nas escolas (AULER e AULER, 2015).

As intervenções analisadas, que mais se aproximaram da perspectiva da abordagem temática, aconteceram de forma pontual e com alguns professores. No entanto, em alguns espaços, os frutos foram sendo cultivados e a disseminação foi possibilitada pelos resultados percebidos, sendo entendido, pela direção de uma das escolas, como necessária a continuidade desse trabalho, mas de forma a abranger toda a escola e professores. 
Considerando as potencialidades identificadas na pesquisa, no âmbito dos avanços observados pelos professores, com relação a suas experiências anteriores, destaca-se o engajamento e o comprometimento com o trabalho coletivo, apontado como algo novo em relação ao seu trabalho anterior. Trabalho coletivo essencial para uma caminhada pela trilha do interdisciplinar. Avançou, com o trabalho temático feito nas escolas, a compreensão que essa concepção curricular não é compatível com ações isoladas de disciplinas. Também houve avanços na diferenciação entre currículos organizados a partir da abordagem conceitual e da abordagem temática. Confirmando os pressupostos trazidos por referências, como exemplo, Auler e AULER (2015); Delizoicov, Angotti e Pernambuco (2011); Meszáros (2005).

O fator motivação foi outra potencialidade identificada, tanto presente entre professores quanto entre estudantes. Esta motivação e engajamento podem ser atribuídos, por exemplo, ao fato do fazer didático-pedagógico estar relacionado com problemas da vida do educando.

Contrariamente as críticas que têm sido apontadas à abordagem temática, um aprendizado mais efetivo e significativo foi apontado entre professores. O processo de aprendizagem foi percebido como algo prazeroso tanto para o estudante quanto para o professor. Houve destaque para o fato de que os conceitos científicos passaram a ser mencionados pelos estudantes em outros momentos, o que sinaliza terem sido apreendidos pelo educando. Também foi destacado potencial da abordagem para que os próprios professores passassem a ter uma maior compreensão de sua própria inconclusão, de seu não saber, de que o conhecimento se constitui de algo inacabado, exigindo constantes buscas.

A partir dos resultados da pesquisa, pode-se verificar que as intervenções curriculares possibilitaram aos professores reverem suas práticas e refletirem sobre elas. Com isso, favoreceu-se o repensar docente e o papel que desempenham na sociedade. Do mesmo modo, entende-se que não será uma única intervenção que mudará o professor, a escola, a sociedade e, o aluno, mas é o início de um longo trabalho, no qual, a partir da disseminação de experiências positivas, possibilitar-se-á o surgimento de intervenções ampliadas. Desta forma sinaliza a necessidade de continuidade desta pesquisa como forma de evidenciar as diferentes contribuições dessa perspectiva de Ensino e Aprendizagem na formação crítica do educando-educador.

\section{REFERÊNCIAS}

ALVES, J. A. P.; MION, R. A.; CARVALHO, W. L. P. Implicações da relação entre ciência, tecnologia, sociedade e ambiente: subsídios para a formação de professores de Física. Experiências em Ensino de Ciências, 4(2), Porto Alegre, 2009, p. 47-59.

ARAÚJO, L. B. A. Os três momentos pedagógicos como estruturantes de currículo. 2015, 150 p. Dissertação (Mestrado em Educação em Ciências: Química da Vida e Saúde)-Universidade Federal de Santa Maria, Santa Maria, RS, 2015.

ARROYO, M. Quem de-forma o profissional do ensino? Revista AEC, ano 14, n. 58, out/dez. 1985.

AULER, D. Articulação Entre Pressupostos do Educador Paulo Freire e do Movimento CTS: Novos Caminhos Para a Educação em Ciências. Contexto e Educação. Ijuí - RS, v. 1, n. 1, 2007, p. 167-188. 
AULER, D.; DALMOLIN, A. M. T.; FENALTI, V. S. Abordagem Temática: natureza dos temas em Freire e no Enfoque CTS. In: Alexandria (UFSC), v. 2 n1, p. 67-84, 2009.

AULER, N. M. F.; AULER, D. (org.) Concepção e execução de currículo no processo formativo de licenciandos do PIBID. Curitiba, PR: CRV, 2015.

BRASIL. Lei $\mathbf{n}^{0}$ 9.394, de 20 de dezembro de 1996. Lei de Diretrizes e Bases da Educação Nacional. Brasil, 1996.

CENTA, F. G. Arroio Cadena: Cartão postal de Santa Maria?: Possibilidades e desafios em uma reorientação curricular na perspectiva da abordagem temática. 2015. 203 p. Dissertação (Mestrado em Ensino de Física)-Universidade Federal de Santa Maria, Santa Maria, RS, 2015.

CENTA, F. G., MUENCHEN, C. O Despertar para uma Cultura de Participação no Trabalho com um Tema Gerador. ALEXANDRIA, Revista de Educação em Ciência e Tecnologia, v. 9, n. 1, p. 263-291, maio 2016.

DELIZOICOV, D. Concepção problematizadora do ensino de ciências na educação formal. 1892. 131 p. Dissertação (Mestrado em Ensino de Ciências)-Universidade de São Paulo.São Paulo: IFUSP/FEUSP, 1982.

DELIZOICOV, D. Conhecimento, Tensões e Transições. 1991, 214 p. Tese (Doutorado em Educação)-Universidade de São Paulo. São Paulo: FEUSP, 1991.

DELIZOICOV, D. Ensino de Física e a Concepção Freireana de Educação. Revista de Ensino de Física, vol. 5, n. 2, dez/ 1983.

DELIZOICOV, D. Uma experiência em ensino de ciência na Guiné Bissau Depoimento. Revista de Ensino de Física, v. 2, n. 4, dez/1980.

DELIZOICOV, D.; ANGOTTI, J. A. Metodologia do ensino de ciências. São Paulo: Cortez, 1994.

DelizOICOV, D.; ANGOTTI, J. A.; PERnAmbUCO, M. C. A. Ensino de Ciências: Fundamentos e Métodos. São Paulo: Cortez, 2011.

DELIZOICOV, D.; ZANETIC, J. A Proposta de Interdisciplinaridade e o seu Impacto no Ensino Municipal de $1^{\circ}$ Grau. In: PONTUSCHKA, N. Ousadia no Diálogo: interdisciplinaridade na escola pública. $4^{a}$ Ed. São Paulo - SP: Edições Loyola, 1993.

FERRÃO, L. V.; AULER, D. Os estudantes do arquivo morto. Revista Educação (UFSM), Santa Maria RS, v. 37, n. 1, jan./abr. 2012, p. 153 - 171.

FREIRE, P. Conscientização: teoria e prática da libertação: uma introdução ao pensamento de Paulo Freire. São Paulo: Cortez \& Moraes, 1979.

FREIRE, P. Educação e atualidade brasileira. Recife: Universidade de Recife, 2001a.

FREIRE, P. Á Sombra desta Mangueira. 5ª edição. São Paulo: Olho d’Água, 2003.

FREIRE, P. A educação na cidade. $7^{a}$ ed. São Paulo: Cortez, 2006a.

FREIRE, P. Pedagogia da autonomia: saberes necessários à prática educativa. Rio de Janeiro: Paz e Terra, 1997.

FREIRE, P. Pedagogia do Oprimido. $17^{\mathrm{a}}$ ed. São Paulo: Paz e Terra, 1987. 
FREIRE, P. Pedagogia dos sonhos possíveis. São Paulo: Editora UNESP, 2001b.

FREIRE, P. Política e educação: ensaios. 6a ed. São Paulo: Cortez, 1997

FREIRE, P; SHOR, I. Medo e ousadia: o cotidiano do professor. $5^{\text {a }}$ ed. Rio de Janeiro: Paz e Terra, 1986.

HALMENSCHLAGER, K. Abordagem de temas em Ciências da Natureza no Ensino Médio: implicações na prática e na formação docente. 2014. 373p. Tese (Doutorado em Educação Científica e Tecnológica)-Universidade Federal de Santa Catarina, Florianópolis, 2014.

HUNSCHE, S.; AULER, D. O professor no processo de construção de currículos: desafios no estágio curricular supervisionado em ensino de física. Revista Eletrónica de Enseñanza de lãs Ciencias. vol. 11, $\mathrm{n}^{0} 1,1-20$ (2012).

JAPIASSU, H. Interdisciplinaridade e Patologia do saber. Rio de Janeiro: Imago, 1976.

MÉSZÁROS, I. A Educação para além do capital. Ed. Boitempo, São Paulo, 2005.

MILITÃO, A. N. Contribuições de Paulo Freire para o debate sobre a formação continuada de professores. In. Encontro de Ensino, Pesquisa e Extensão: Colloquium Humanarum, vol. 9 n. Especial, Presidente Prudente, SP., 2012.

MORAES, R. Cotidiano no Ensino de Química: superações necessárias. In: GALIAZZI, M. C., AUTH, M. A.; MANCUSO, R. (p. 15-34). Aprender em Rede na Educação em Ciências. Ijuí: Editora Unijuí. 2008.

MORAES, R. Uma tempestade de luz: a compreensão possibilitada pela análise textual discursiva. Ciência \& Educação: Bauru, SP, v. 9; n. 2; p. 191-210; 2003.

MORAES, R; GALIAZZI, M. C. Análise Textual Discursiva. Ijuí: UNIJUÍ, 2011.

MORAES, R; GALIAZZI, M. C. ANÁLISE TEXTUAL DISCURSIVA: processo reconstrutivo de múltiplas faces. Ciência \& Educação, v. 12, n. 1, p. 117-128, 2006.

MORAES, R; GALIAZZI, M. do C. Análise Textual Discursiva. Ijuí: Ed. Unijuí, 2013.

MUENCHEN, C. A disseminação dos Três Momentos Pedagógicos: um estudo sobre práticas docentes na região de Santa Maria/RS. 2010. 273p. Tese (Doutorado em Educação Científica e Tecnológica)-Universidade Federal de Santa Catarina. Florianópolis, SC, 2010.

MUENCHEN, C.; DELIZOICOV, D. A CONSTRUÇÃO DE UM PROCESSO DIDÁTICOPEDAGÓGICO DIALÓGICO: ASPECTOS EPISTEMOLÓGICOS. Ensaio Pesquisa em Educação em Ciências, vol. 14, núm. 3, septiembre-diciembre, 2012, p. 199-215. UFMG, Brasil.

NÓVOA, A. Formação de professores e profissão docente. In: NÓVOA, A. (org.). Os professores e a sua formação. $2^{\mathrm{a}}$ ed. Lisboa: Dom Quixote, p.13-33, 1995.

PERNAMBUCO, M. M. C. A. Educação e escola como movimento: do ensino de ciências à transformação da escola pública. 1994. Tese (Doutorado em Educação)-Universidade de São Paulo. São Paulo, 1994.

PERNAMBUCO, M. M. C. A., DELIZOICOV, D., ANGOTTI, J. A. P. Projeto ensino de Ciências a partir de problemas da comunidade. In: Atas do seminário Ciências Integrada e/ou Integração entre as Ciências: teoria e prática. Rio de Janeiro: Editora UFRJ, 1988. 
, M. M. C. A.. Significações e realidade: conhecimento (a construção coletiva do programa) In: PONTUSCHKA, N. (org.) Ousadia no diálogo: interdisciplinaridade na escola pública. São Paulo: Loyola, 1993.

SAMPAIO, M. M. F.; QUADRADO, A. D.; PIMENTEL, Z. P. Interdisciplinaridade no Município de São Paulo. Brasília - DF: INEPE, 1994.

SANTIAGO, M. E.; BATISTA N., J. Formação de professores em Paulo Freire: Uma filosofia como jeito de ser-estar e fazer pedagógicos. Revista e-curriculum, São Paulo, v. 7 n. 3. Edição especial de aniversário de Paulo Freire. 2011.

SANTOS, W. L. P. Scientific Literacy: A Freirean Perspective as a Radical View of Humanistic Science Education. Science Education, v. 93, p. 361-382, 2009.

SÃO PAULO. Cadernos de Formação 01, 02, 03. Série Ação Pedagógica na escola pela via da interdisciplinaridade. Secretaria Municipal de Educação. São Paulo: DOT/SME-SP, 1990.

SÃO PAULO. Visões de área: Ciências. Coleção de autores coletivos. Secretaria Municipal de Educação. São Paulo, DOT/SME-SP, 1992.

SILVA, A. F. G. Das falas significativas às práticas contextualizadas: a construção do currículo na perspectiva crítica e popular. Tese (doutorado), São Paulo: PUC, 2004.

STRIEDER, R. B.; CARAMELLO, G. W. ; HALMENSCHLAGER,K. R.; FEISTEL, R. A. B.; GEHLEN, S. T. Abordagem de Temas na pesquisa em Educação em Ciências: pressupostos teórico-metodológicos. In: Atas do VIII Encontro de Pesquisa em Educação em Ciências. Campinas - SP, 2011.

TORRES, J. R.. Educação Ambiental Crítico-Transformadora e Abordagem Temática Freiriana. Florianópolis: UFSC, 2010. (Tese doutorado).

VASCONCELOS, C. S. Planejamento: plano de ensino-aprendizagem e projeto educativo. São Paulo: Libertad, 1995.

WATANABE-CARAMELLO, G; KAWAMURA, M. R. D. Uma abordagem temática para a questão da água. In: Atas do X Encontro de Pesquisa em Ensino de Física. Londrina - PR, 2006.

\section{NOTAS}

${ }^{1} \mathrm{O}$ referencial teórico assumido, no presente artigo, constitui uma das formas de Abordagem Temática, ou seja, a Abordagem Temática Freireana (ATF). Em abordagens CTS, CTSA, questões ou controvérsias sociocientíficas, muitas vezes, o trabalho também tem sido fundamentado em temas, mas não necessariamente geradores. Nesse contexto, pode-se citar interessante trabalho de Santos (2009). Conforme explicitado no referencial teórico, geradores porque exigem um processo de investigação da realidade, gerando currículos as partir de contradições sociais mais amplas presentes na comunidade.

${ }^{2}$ A definição do Tema Gerador pode ser realizada, basicamente, a partir de 3 perspectivas:

- Investigação Temática (FREIRE 1987), a qual foi transposta por Delizoicov (1982, 1991) para a educação formal. Nesse momento, descrita resumidamente como: Levantamento preliminar da realidade local; Análise das situações e escolha das codificações; Círculos de investigação temática; Redução temática e a última etapa, conforme descrito por Muenchen (2010), foi apontado por Delizoicov, em sua dissertação (1982) e tese (1991), a partir da releitura de obras de Freire, sendo essa a etapa que ocorre em sala de aula. Freire (1987) expressa a dinâmica da investigação temática mais sistematicamente em sua obra "Pedagogia do Oprimido"; 
- Três Momentos Pedagógicos (3MP) como estruturantes de currículos (MUENCHEN, 2010; MUENCHEN e DELIZOICOV, 2012; ARAÚJO, 2015, CENTA e MUENCHEN, 2016), constituídos de: Estudo da Realidade (ER), Organização do conhecimento (OR) e Aplicação do Conhecimento (AC);

- Práxis Curricular via Tema Gerador (SILVA, 2004).

${ }^{3}$ Entende-se que configurações curriculares, estruturadas mediante a ATF, podem contribuir para a constituição de um sujeito leitor crítico da realidade, na perspectiva de seu engajamento para a transformação dessa realidade. Contudo, há um conjunto de adversidades e limitações a serem consideradas, analisadas criticamente e, se possível, superadas. Esse conjunto de adversidades e limitações é denominado de desafios.

${ }^{4}$ Se há desafios no processo de formação/constituição de um sujeito com capacidade de realizar uma leitura crítica da realidade, nessa pesquisa, busca-se, também, estabelecer um processo reflexivo sobre possibilidades encontradas, sobre possíveis caminhos para a superação desses desafios. Essas possibilidades, esses caminhos são denominados de potencialidades.

${ }^{5}$ Todos os participantes da entrevista assinaram o Termo de Consentimento Livre Esclarecido (TCLE)

${ }^{6}$ Nesse caso, mesmo tendo ocorrido uma configuração curricular por temas, uma Abordagem Temática (AT), não se pode falar em Abordagem Temática Freireana (ATF). O que caracteriza esta última é a investigação do tema junto aos estudantes, junto à comunidade em que vivem. Não é o caso quando o professor/pesquisador define, "leva" o tema.

\section{Submetido em 28/03/2018}

Aprovado em 23/10/2018

\section{Contato:}

Avenida Saydi Abrahão, n. 175, ap 901 - Centro

CEP 95.590-000 - Tramandaí, RS - Brasil 